\title{
Reviews on Books and Media
}

\section{Buryakovsky L, Chilingar GV, Reike HH and Shin S: Fundamentals of the petrophysics of oil and gas reservoirs}

\author{
Lee C. Gerhard
}

(C) Springer-Verlag Berlin Heidelberg 2012

\section{2 | John Wiley \& Sons/Scrivener Publishing LLC | 400 pp | 193 figs | Hardback EUR 169.00 | USD 195.00 | ISBN 978-1-118-34447-7}

Fundamentals of the Petrophysics of Oil and Gas Reservoirs is just that. For students, it is an introduction to the basic concepts of petrophysics, a discipline not often taught in undergraduate curricula. For the practitioner it is a reminder of rock attributes that can be exploited for higher percentage recoveries from oil and gas reservoirs. Geologists will appreciate the review of engineering principles of rock attributes and seismicity, engineers will appreciate the basic review of geologic rock qualities, geophysicists can learn more about the rock parameters that determine reflection characteristics and velocity.

As the book title advertises, the authors have focused on oil and gas reservoirs. Introductory sections of the book treat characteristics of petroleum reservoirs and lithologies, followed by petrophysical parameters, porosity and density, permeability and specific surface area. Field examples of the interrelationships of these parameters are documented by field studies from Russia and Central Asia.

The book goes on to study rock wettability, elastic properties, acoustic properties, resistivity and radioactivity. The last major technical section of the book is devoted to seismic parameters and the effects of petrophysical properties on seismic methodology.
All of these sections are a useful review for the practitioner and a basic introduction for students. Coupled with the lucid text are both an extensive glossary and exhaustive bibliography, both enabling the serious student to pursue any of the topics.

The authors have included three appendices. The first, by Donald Hill, is a detailed history of petrophysics complete with examples and explanations, one of the features of the book that provides the background for petrophysics studies. Even an expert will enjoy the review and perspective presented.

Appendix B is an explanation and study of the mechanics of fluid flow. This appendix includes problem solutions that illustrate the principles discussed. The final appendix is the glossary, a very handy guide and reminder of the technical definitions of oilfield vernacular.

Although written primarily for the petroleum student and practitioner, this book's broad application will prove itself valuable to environmental geologists and hydrologists. Recent rapid advances in rock parameter measurement technology based on petrophysics have greatly enhanced the ability to model and predict fluid behavior.

This review volume can be very useful to many scientists, not just to those involved with petroleum exploration and production and should be a handy reference for all. 